\title{
NÚCLEO DE COMUNICAÇÃO E EDUCAÇÃO PROMOVE CONGRESSO INTERNACIONAL
}

Assistimos, nos dias atuais, a um verdadeiro despertar de importantes segmentos da sociedade - incluindo órgãos públicos, empresas, escolas, ONGs e centros culturais - em torno do uso da Comunicação na Educação.

Foi, por exemplo, graças à mobilização de educadores, comunicadores e empresários que a recente legislação sobre radiodifusão (Lei da TV por Cabo) definiu como obrigatória a abertura de canais para a educação em todos os sistemas a serem implantados no Brasil nos próximos anos.

Observa-se, de fato, que quase todos os grandes projetos de Educação implantados na última década mantêm algum grau de envolvimento com o sistema de meios de informação e com as tecnologias de ponta, como é o caso da TV Escola do Governo Federal e da TV Futura, mantida por um pool de 17 grandes empresas, articuladas pela Fundação Roberto Marinho. Em outras palavras: certificamo-nos de que, cada vez mais, a inter-relação Comunicação / Educação se consolida como campo de produção e de intervenção cultural em favor de uma educação de qualidade.

\section{O AUTOR}

\section{Ismar de Oliveira Soares}

Coordenador do Núcleo Comunicação e Educação do Departamento de Comunicaçōes e Artes da ECA-USP. Vice-presidente para a América Latina do World Council for Media Education. E-mail: ismar@usp,br
Por seu lado, os meios de informação se aperceberam de que Educação, além de ser essencial ao desenvolvimento de um país, pode transformar-se em produto de legitimação social, favorecendo um possível diálogo com os usuários de seus produtos. Basta recordar o sucesso que vem alcançando o programa $\mathrm{O}$ jornal em sala de aula, objeto de recente congresso internacional em São Paulo e que mobiliza dezenas de periódicos no Brasil e mais de 700 veículos impressos nos Estados Unidos.

As relações que unem e/ou confrontam o sistema de meios e a Educação têm sido, também, objeto de preocupação por parte de pais e educadores, quando observam que o atual momento civilizatório vem mergulhando as novas gerações no que hoje se denomina como a Era da Informação, com todas as suas conseqüências culturais, políticas e sociais. Nesse sentido, os estudos voltados para o campo da recepção das mensagens tentam descobrir como reagem as crianças e os jovens frente ao impacto dos meios de comunicação.

É a partir deste contexto que um grupo de professores do Departamento de Comunicações e Artes da ECA-USP decidiu criar o Núcleo de Comunicação e Educação, que reúne pesquisadores e especialistas da USP e de outras instituições universitárias, assim como produtores culturais e professores que desenvolvem projetos que levam em conta a presença dos meios de comunicação na sociedade. 
O NCE desenvolve, como sua atividade central, uma pesquisa voltada a identificar o perfil dos estudiosos e dos agentes culturais dedicados aos vários campos da inter-relação Comunicação Social/ Educação. Promove reuniões periódicas com seus membros, nas quais são analisados projetos de pesquisa em desenvolvimento, assim como programas de intervenção cultural promovidos, no Brasil e no exterior, pelos especialistas da área.

Entre as atividades do NCE destaca-se seu programa de cursos de extensão universitária, denominado Programa de Educação para a Comunicação (um total de 50 títulos de cursos de 32 horas, cobrindo os vários campos onde a Comunicação interage com a Educação, ministrados nos locais indicados pelas entidades contratantes). Os cursos, oferecidos às redes pública e particular de ensino, cobrem tanto a área da comunicação como produção cultural, quanto a área da aplicação das tecnologias da informação ao ensino.

O NCE representa no Brasil o World Council for Media Education (W.C.M.E.), entidade criada na Espanha, em 1996, e dedicada a promover práticas pedagógicas no campo da educação para a recepção crítica e ativa das mensagens dos meios de comunicação.

O NCE encontra-se aberto para receber e dialogar com todos os interessados em legitimar e fazer crescer os vários âmbitos das possíveis inter-relações entre Comunicação Social e Educação.

A principal atividade do NCE em 1998 será a realização - entre os dias 20 e 24 de maio, em São Paulo, em co-patrocínio com o W.C.M.E., o Instituto Cultural Itaú (ICI) e o Serviço Nacional do Comércio
(SENAC-SP) - de dois importantes eventos: o II Encontro Mundial sobre Educação para os Meios e o I Congresso Internacional sobre Comunicação e Educação, para os quais estão sendo esperados participantes provenientes de mais de 30 países dos cinco Continentes. Já confirmaram presença pesquisadores da África do Sul, Alemanha, Argentina, Austrália, Chile, Colômbia, Dinamarca, Espanha, Estados Unidos, Índia, Itália, Japão, México, Nepal, Portugal, Palestina, Reino Unido, Rússia, Suécia, Uruguai, Venezuela, entre outros.

Durante o Congresso Internacional sobre Comunicação e Educação serão prestadas homenagens a dois ilustres brasileiros falecidos recentemente: Paulo Freire, por sua contribuição para a compreensão da natureza comunicacional dos processos educacionais e Herbert de Sousa, por suas contribuições para o uso da comunicação na promoção da cidadania.

\section{CONGRESSO INTERNACIONAL SOBRE COMUNICAÇÃO E EDUCAÇÃO}

O Congresso tem como objetivo examinar as experiências internacionais no campo do uso das tecnologias da comunicação na educação, tanto para o desenvolvimento da liberdade de expressão quanto para a promoção da cidadania. Com isso o NCE pretende oferecer uma contribuição específica destinada a introduzir a discussão sobre a comunicação nas celebrações dos 50 anos da Declaração dos Direitos Humanos.

Para o atendimento de necessidades emergentes no campo da atualização do magistério, serão organizados workshops desti- 
nados a atualizar professores e agentes culturais nos vários campos da inter-relação entre Comunicação e Educação. Para tanto, serão convocados ao redor de 40 especialistas de renome internacional.

Atenção especial será dada às crianças e adolescentes, através de atividades culturais que possibilitem às novas gerações a experimentação do fenômeno da comunicação como exercício da leitura crítica dos meios de comunicação. Tais atividades, programadas tanto para o espaço do ICI quanto para o espaço do SESC-Pompéia, se realizarão durante os meses de maio e junho do próximo ano.

Resumo: $\mathrm{O}$ artigo trata dos fundamentos, objetivos e atividades do Núcleo de Comunicação e Educação, do Departamento de Comunicações e Artes da ECA-USP, coordenado pelo Prof. Dr. Ismar de Oliveira Soares, vice-presidente do World Council for Media Education. Destaca as principais atividades do Núcleo para 1998: o Congresso Internacional sobre Comunicação e Educação e o II Encontro Mundial sobre Educação para os Meios, ambos a serem realizados em maio de 1998, com o apoio de inúmeras instituições.

Palavras-chave: Comunicação e Educação, Educação para os Meios, Congresso, Encontro.
A coordenação geral dos trabalhos está sob a responsabilidade do coordenador do NCE, Prof. Dr. Ismar de Oliveira Soares e conta com o apoio das seguintes instituições: Escola de Comunicações e Artes da USP, Instituto Cultural Itaú, Serviço Nacional do Comércio - SESC-São Paulo, Revista Imprensa, TV Cultura-SP, TV SENAC.

Maiores informações sobre o Congresso Internacional sobre Comunicação e Educação devem ser solicitadas ao: Núcleo de Comunicação e Educação, Departamento de Comunicações e Artes da ECA-USP. Fone: (011) 818-4081 e Fax: (011) 8184326. E-mail: ismar@usp.br.

Abstract: The article deals with the bases, objectives and activities of the Nucleus of Communication and Education of ECA-USP's Department of Communications and Arts, coordinated by Dr. Ismar de Oliveira Soares, vice-president of the World Council for Media Education. It emphasizes the Nucleus's main activities for 1998: the Communication and Education International Congress and the II World Meet on Education for the Media, both to be carried out in May, 1998, in São Paulo, and sponsored by countless institutions.

Keywords: communication and education, education for the media, Congress, Meet 